\title{
Nourishing nations during pandemics: why prioritize fish diets and aquatic foods in Africa
}

\author{
Ahmed Khan ${ }^{1}$. Siham Mohamed Ahmed ${ }^{1}$. Cheikh Sarr ${ }^{1}$. Youssouf Kabore ${ }^{1}$. Gracia Kahasha ${ }^{1}$. \\ Lewis Bangwe ${ }^{1} \cdot$ Walter Odhiambo ${ }^{1} \cdot$ Nathalie Gahunga $^{2} \cdot$ Bernice Mclean $^{3} \cdot$ Hamady Diop $^{3} \cdot$ Hellen Moepi $^{3}$. \\ Mohamed Seisay ${ }^{4} \cdot$ Amadou Tall $^{5}$. Eshete Dejen ${ }^{6} \cdot$ Motseki Hlatshwayo $^{7} \cdot$ Anna Lartey $^{8} \cdot$ Pascal Sanginga $^{8}$. \\ Ndiaga Gueye $^{8}$ - Alison Amousso ${ }^{9}$ - Abou Bamba ${ }^{9}$ Mutinta Hambayi ${ }^{10}$ - Ali Kamal-Deen ${ }^{11} \cdot$ Harrison Karisa $^{12,13}$. \\ Bernadette Fregene $^{13} \cdot$ Victor Siamudaala $^{13}$. Shakuntala Haraksingh Thilsteld ${ }^{13}$
}

Received: 6 January 2021 / Accepted: 29 July 2021 / Published online: 24 August 2021

(c) The Author(s), under exclusive licence to Springer-Verlag GmbH Germany, part of Springer Nature 2021

\begin{abstract}
The COVID-19 pandemic caught the world unprepared, with containment measures impacting both global supply chains and agri-commodity flows. The public health crisis raised some urgent questions: "how can fish and other aquatic foods and supply chains be prioritized as health-related interventions to avert both a malnutrition crisis and gender inequality?" Furthermore, "what are the integrated responses, investment opportunities, and governance mechanisms to effectively address the pandemic?" As "super foods," diets of fish and aquatic foods provide animal-source protein, omega-3 fatty acids, and micronutrients, including both vitamins and minerals, necessary for both the ill and the healthy. The affordability and accessibility of fish could address food and nutrition security needs under lockdown and border closures, boost immune systems, and increase commodity trade. This analytical piece focuses on the continent of Africa, where malnutrition is pervasive, but also where local aquatic food supplies can be utilised during lockdowns and border closures. The paper provides governance insights on national budget support programs and portfolio restructuring to strengthen local aquatic foods production systems to meet dietary needs. Furthermore, the authors advocate for a coordinated multi-sectoral intervention across several wellbeing domains in the immediate and medium-term involving various partnerships. These integrated responses will mutually limit the contagion while providing support to functional fish value chains for healthy diets, livelihoods, cross-border trade, and long-term macroeconomic recovery.
\end{abstract}

Keywords Fisheries $\cdot$ Aquaculture $\cdot$ COVID-19 $\cdot$ Healthy diets $\cdot$ Food and nutrition security $\cdot$ Partnerships $\cdot$ Investments Africa

This is a collaborative and supplementary contribution to the African Development Bank Group 'Feed Africa Response to Covid-19 (FAREC)' road map, expounds on aquatic food systems in the Blue Economy towards nutrition, livelihoods, and regional trade.

Ahmed Khan

a.khan@afdb.org

1 Department of Agricultrure and Agro-Industry, Agribusiness Division, AfDB, Abidjan, Côte d'Ivoire

2 Department of Gender, Women and Civil Society, AfDB, Abidjan, Côte d'Ivoire

3 AUDA-NEPAD, Midrand, South Africa

4 AU-IBAR, Nairobi, Kenya

5 PESCAO-ECOWAS, Abuja, Nigeria

6 IGAD, Djibouti City, Djibouti
7 SADC, Gaborone, Botswana

8 United Nations Food and Agriculture Organization, Rome, Italy

9 United Nations Environment Programme/Abidjan Convention, Abidjan, Côte d'Ivoire

10 United Nations World Food Programme, Rome, Italy

11 CEMLAWS Africa, Accra, Ghana

12 World Bank Group, Washington, DC, USA

13 WorldFish, Penang, Malaysia 


\section{Introduction}

The COVID-19 pandemic, a public health crisis, additionally has ramifications on every fibre of society and the economy. The crisis has exacerbated food and nutrition insecurity, especially in Africa (GFSC 2020). This leaves more than 200 million hungry and vulnerable and where concurrent challenges of fragility, climate-related droughts and floods, natural disasters, and pest infestations are evident. Understanding the food-nutrition-health nexus is important in exploring holistic interventions to this pandemic. Fish and other aquatic foods in diets have a crucial role in nourishing nations and addressing food and nutrition security (Bennett et al. 2020). Fisheries provide food to more than three billion people worldwide, with trade volumes exceeding USD 160 billion per year (FAO 2020a). Although fish is often the only source of protein for many Africans, particularly in riparian regions, the continent's consumption and production of fish are the lowest in world. The World Health Organization (WHO) recommends fish consumption level at $15 \mathrm{~kg} /$ capita, which is still unmet in Africa (FAO 2020a), with current consumption at about half the global average (about $10.6 \mathrm{~kg} / \mathrm{capita} /$ year).

As argued in one of the commentaries to the Manifesto for the Marine Social Sciences (Bavinck and Verrips 2020), fisheries have a unique transformational development impact on food and nutrition security, well-being, and macroeconomic development (Khan 2020). They have the potential for gender transformation and women's empowerment along the fish supply chain (Frangoudes et al. 2020). When secondary elements such as processing and trading are included, women account for more than $50 \%$ workers in the capture fisheries and aquaculture supply chains, thus providing a rationale for gender empowerment (Harper et al. 2013), yet women face substantive challenges towards social protection and financing to engage and benefit equitably from these sectoral activities. At play are a combination of factors, including limited access to and control over assets and resources, constraining gender norms, time and labor burdens of unpaid work, and barriers to sustaining entrepreneurship.

Within the context of the pandemic, fisheries are even more important for their dietary and health benefits, as well as livelihood and community health (Bennett et al. 2020). On a continent with net deficit of fish production, fisheries could alleviate this, and farming, harvesting, and processing would increase shelf life of foods, create jobs, and feed a hungry population. In times of crisis, where human populations are at an increased susceptibility to diseases, the role of fish as a "super food" cannot be overemphasized owing to its nutritional content (Thilsted et al. 2016; Belton et al. 2021), especially its function role in grey matter infrastructure and boosting immune systems (AfDB 2018; Hicks et al. 2019).
Given the importance of fisheries, aquaculture, blue ports, and maritime trade to the Blue Economy (Bennett et al. 2019), addressing the pandemic beyond health interventions is critical for macroeconomic stabilization. They also provide unique opportunities to address the food import gap through local production and intra-regional trade. Therefore, it is vital to support functional food supply chains, especially capture fisheries and aquaculture, as part of immediate and short-term COVID-19 response strategies in regions where fish is an integral diet and as a locally traded commodity (Bolton et al. 2021).

In this paper, we first review the COVID-19 impacts; provide a rationale for strengthening food-nutrition-health nexus; assess response interventions across various fish production systems; conclude with medium- and long-term strategic recommendations. Overall, this paper advocates for investments that are nutrition-sensitive on the African continent and that can support myriads of livelihoods, nutritional well-being, intra-regional trade, and inclusive and resilient economies.

\section{COVID-19 impacts on global supply chains and food-health implications}

COVID-19 is occurring against a backdrop of existing high levels of malnutrition and vulnerabilities. This is especially apparent across sub-Saharan Africa where there is strong reliance on food imports. About $80 \%$ of commodities are transported through maritime corridors on the African continent, and the interruption in maritime food production chains will lead to further reductions in food consumptionespecially among the most vulnerable (Swinnen 2020). The pandemic also has a huge impact on local production and the accessibility of inputs. For fisheries systems, these impacts range from low landings at the dock due to limited fishing activities, to loss of jobs and income from lockdowns and social distancing. Additionally, lack of access to fishing inputs and feeds for fishing/farming operations, non-functional cold storage networks, and post-harvest loss and food waste are all evidence of production constraints. Moreover, labour shortage for onshore and offshore operations, increasing food prices, and disruption in shipping traffic has affect food availability.

Drawing on the framework of the High-Level Panel of Experts (HLPE) on Food Security and Nutrition (HLPE 2014; 2017) improved food systems need to consider all policy-related elements of food supply chains, the food environment and consumer behavior. With an emerging economic recession and yet still reliance on fish imports, during disruption in supply chains, concerns about increase in food price will affect food and nutritional wellbeing. Novel interventions will require complementary nutrition 
sensitive interventions to mitigate the impact. There is an equally increasing demand for other nutrition sensitive diets including livestock products, which can contribute to food security and the resilience of rural livelihoods (HLPE 2016). Compared to 4.8 billion USD imports of fish products in 2017, the value of fish exports alone was estimated at 11 billion USD, an estimated $8.5 \%$ of global fish exports, with most countries showing deficit in production. Most developing countries export high value fish products such as large pelagics and shellfish while importing mostly small pelagics (Smith et al. 2010).

Despite the rich aquatic food resources across six Large Marine Ecosystems (LMEs) on the African continent, in addition to numerous lakes (Chad, Malawi, Tanganyika, Victoria) and major rivers (including the Nile, Congo, and Niger), undernourishment and micronutrient deficiencies are still prevalent (Kolding et al. 2019). Most fish commercial species produced are targeting European markets, with a complementary intra-regional trade playing a crucial role for regional access to land-locked countries (Fig. 1). While most of the frozen ocean fish is traded in urban and peri-urban settings such as Abidjan in Cote d'Ivoire in West Africa, most of the dried ocean fish are traded along intra-regional routes across borders to landlock urban settings such as in Bamako in Mali. As shown in the broken black lines in Fig. 1, cold room networks and transportation connectivity are some of the constraints in cross-border trade in Africa.

What is less discussed is the role of various financing instruments to facilitate productivity along the food-nutrition-health nexus during the pandemic. Lessons from previous shocks and crises such as Ebola (2015), SARS (2010), the global food crisis (2008) included fiscal measures in terms of investment programs, but also policy reform and technical advisory support to food and nutrition security and well-being (Larson 2002). As the pandemic unfolds, diets can shift away from fresh fish and other aquatic foods, and become dominated by staple foods, canned foods, and non-perishable foods, with concerns about malnourishment (Global Nutrition Report 2018).

Moreover, today's food systems are more focused on quantity rather than quality. Hence, consumers are not making healthy and affordable food choices for good nutrition. Analysis of the multiple burdens of malnutrition within nations now provides insights into the degree to which countries and people experience multiple forms of malnutrition such as wasting and stunting (Walson and Berkley

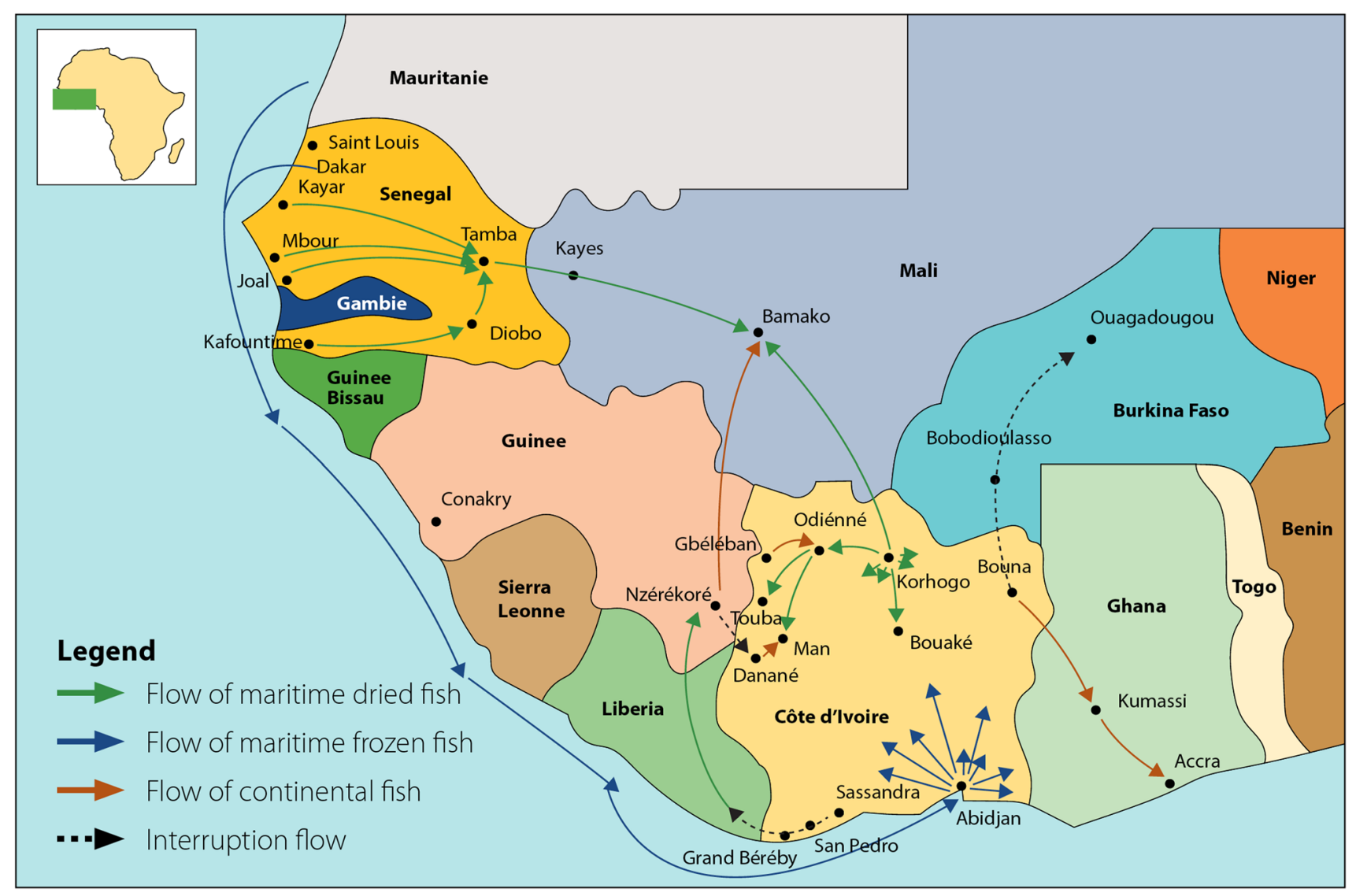

Fig. 1 Local fish trade and cross-border supply networks pre-COVID-19 (Ayilu et al. 2016) 
2018). Poor diets have been identified as the leading cause of disease, death, and disability (Black et al, 2008; Global Nutrition Report, 2020). To ensure nutritious diets, appropriate and safe foods that include adequate micro- and macronutrients must be available to the most vulnerable, and to the societies during crisis periods. Current observations show that individuals with diet-related non-communicable diseases, including heart disease, hypertension, and diabetes, are more likely to develop more severe symptoms and complications when infected with COVID-19 (FAO 2020b).

Adequate investment in food systems to increase nutrient value of foods, along supply chains in the processing and storage of perishable foods including refrigeration in periurban and drying in rural areas will improve diet quality and quantity (AU-IBAR 2018). In response to the COVID-19 pandemic, governments have rolled out programs largely aimed at addressing the resulting short-term health concerns and to provide stimulus packages to sustain economies and address social protection issues. These may provide opportunities for investment and long-term economic recovery in enhancing production, value addition and cross-border trade. However, many African governments are already in financial stress due partly to their seriously affected fiscal revenues because of the crisis and the large and growing external financing needs. Hence, Development Financial Institutions (DFIs) have prioritised emergency and fast-track concessional financing.

\section{Exploring policy entry points and targeted interventions for COVID-19}

For the prioritization of nutrition sensitive diets and related investments, multiple entry and exit points are needed to transformative actions (HLPE 2014). From a food systems perspective, an integrated approach is warranted to maximise the production, transformation, and consumption of these agri-commodities in support of healthy diets and nutrition outcomes. Given the contribution of agriculture, fisheries, and livestock to rural development and inclusive economies, policy dialog and technical assistance can complement the short-term response to cater to food and nutrition security and long-term economic recovery.

From a health perspective, a review of the literature indicates that "well-being" is the most appropriate entry point for dietary and value chain interventions on COVID-19 given its multiple domains of influence. This includes food and nutrition security, physical and emotional health, social and cultural ties, and economic and financial domains as shown in Fig. 2.

Hence, direct food assistance that includes canned or cured fish is imperative, in addition to support to local supply chain actors and facilitating regional food corridors to the most vulnerable and undernourished could be part of immediate to short-term dietary responses (Fig. 2: top left quadrant). Accordingly, food and nutrition security and
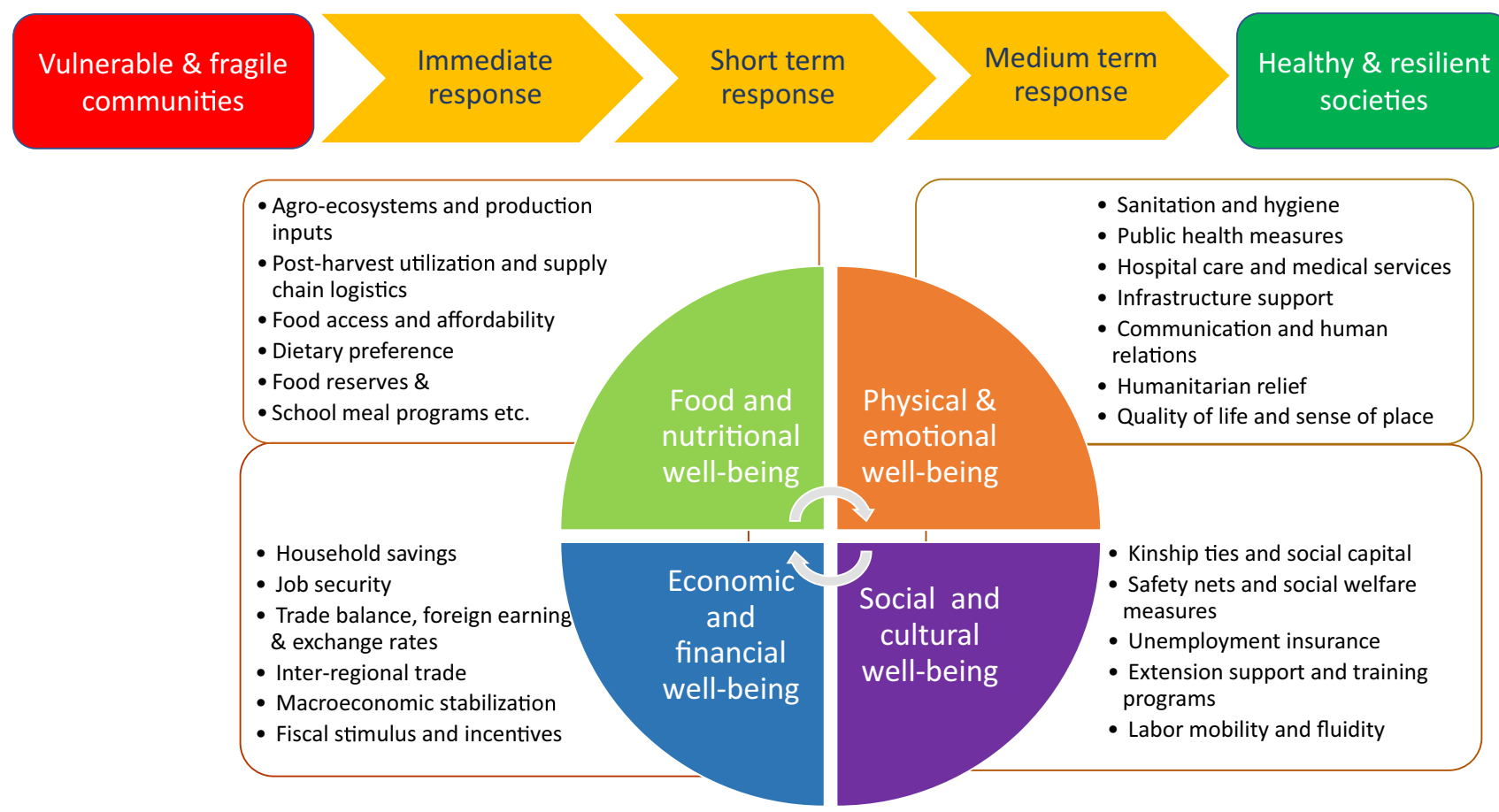

Fig. 2 Policy entry points for targeted and integrated responses to COVID-19 impacts 
well-being are strongly linked to materiality (income and household assets), relational ties (union support, cooperatives and fisher associations), and subjective well-being, including a sense of place and aspirations (Coulthard et al. 2011). Knowing that social well-being has been fully embedded within the discourse on the governance of fisheries (Johnson et al. 2018), it is imperative to make stronger synergies between food and nutrition security and fiscal policies (OECD 2014; FAO 2020c). Fiscal support through loans and grants, trade debt repayments, and budget support can contribute to the response through macroeconomic stabilization and long-term economic recovery (Fig. 2: lower left quadrant). Similarly, safety nets and kinship ties are crucial for building social capital during shocks, as well as securing livelihoods through social protection measures (Fig. 2: bottom right quadrant).

However, proposed and actual interventions on the African continent are not uniform. Policy responses may depend on geographical location, resource endowment, production and supply chain networks, human capital, gender inequality, and institutional capacity. For instance, in Large Ocean Area Countries or Small Island Developing States (SIDS), physical remoteness and climate vulnerability are constraints to maritime connectivity and regional trade. These SIDS are dependent on the blue economy (fisheries, tourism, and shipping) that creates national revenue and household income, and often reliant on Foreign Direct Investments (FDIs). Disruptions in sea freight and logistical supply will continue to affect commodity flows and thereby increase importation costs, especially for food and related products. A similar issue can be portrayed for fisheries-dependent, land-locked, and riparian states that rely on waterways and on-land transportation routes for input supply as well as output logistics for regional market access. For coastal states, issues regarding shared and migratory fish stocks such as tuna, maritime security especially for offshore fishing fleets, and access rights for inshore small-scale fishers (SSF) are critical to addressing the pandemic (FAO 2015; Jentoft and Chuenpagdee 2009).

Another efficient entry point to COVID-19 response will be to reduce gender inequalities and enhance women's participation as equal and productive partners in the fisheries and aquaculture value chains. This includes macro-level policy solutions through gender budgeting as well as responsible governance of tenure security and access (FAO 2013). This can be achieved through deliberate and concerted efforts towards women's participation in resource management initiatives, such as enabling greater access to resources, control of input supplies and services, guaranteeing their rights of access to fisheries resources, upgrading and enhancing their technical skills, and improving their access to financial and non-financial services. In southern and western African regions, there have been regional approaches on promoting gendered management of post-harvest losses as well as creating business development platforms to support cooperatives and SMEs. Women have been found to be more susceptible to the negative impacts of post-harvest losses than their male counterparts. This is because of their huge involvement in post-harvest value chains activities, where the bulk of post-harvest losses occur (SADC, 2020).

Immediate and medium-term strategies are required for fish production from capture fisheries and aquaculture, in addition to processing, curing, and cold storage infrastructure. It also requires facilitating women's control over these fish production assets and resources. Here, solar panels and the FAO-Thiaroye fish processing technique (FTT-Thiaroye) could be easily deployed to address post-harvest loss for women's SMEs, increasing the quantity of fish to feed local households, supply regional markets, and improve overall well-being.

Looking into the future, novel policy entry points should focus on (i) strengthening the regulatory environment to circumvent production and trade flow disruption during crisis within the framework of the African Continental Free Trade Agreement (AfCTA); (ii) promote standards and safety for border customs and clearance such as the 'One Stop Border Post' model; (iii) promote policies that rely on digital technologies to improve information systems and e-commerce.

\section{Investing in functional food-nutrition-health systems}

As highlighted earlier, the concurrent impact of COVID-19 and a looming economic recession could exacerbate food and nutrition security, especially among the poor, through rising food prices, falling incomes, and poor accessibility. Acknowledging that malnutrition impairs specific immune function and increases susceptibility to infections, dietary intake should be included as a measure of health and wellbeing, as well fiscal incentives towards effective supply chain. In times of crisis and global shocks, such as Ebola and Cyclone Idai, various fiscal measures have been employed, including investments in health infrastructure, strengthening food systems, and supporting disaster relief programs (Khan and Sesay 2015). In the case of COVID-19, this could be guided by an all-inclusive partnership, and collaboration supports which offer appropriate interventions that are inclusive, fair, and efficient (Bennett et al. 2019). To this effect, multilateral development banks and development financing institutions, together with development partners, are formulating strategies and financing instruments in response to food and nutrition security as well as strengthening health infrastructure and delivery services. These commitments are also aligned with the continent's development programs. 
Recent COVID-19 responses include the African Development Bank Group (AfDB) 10 billion USD COVID-19 Response Facility, which entails crisis-response budgetary support and a commitment to ensuring that these operations are fast-tracked to enable a timely response. Similarly, the World Bank has committed 160 billion in grants and financial support over a period of 15 months to support developing countries to respond to the effects of the COVID-19 pandemic. Over one hundred countries are expected to benefit, of which 39 are in Africa. The IMF has also extended crisis support through its Rapid Credit Facility to many African countries. The Africa Export and Import Bank provided a 3 billion USD COVID-19 Trade Impact Mitigation Facility to support debt repayments and currency stabilization through multiple financial instruments including lines of credit, direct funding, guarantees, and cross-currency swaps. Likewise, the West African Development Bank provides soft loans up to USD 197 million and suspension of debt repayment on principal to about USD 125 million (AfDB, 2020).

These response strategies will complement and support various policy and governing frameworks including African Union Agenda 2063, the Sustainable Development Goals (SDGs), the Malabo Commitments and the Comprehensive Africa Agriculture Development Programme (CAADP), the African Union Development Agency - New Partnership for African Development (AUDA-NEPAD) Policy Framework and Reform Strategy for Fisheries and Aquaculture, and various regional strategies (e.g., ECOWAS Commission 2019) and the SADC Regional Indicative Strategic Development Plan (2020-2030). In 2019, the African Leaders for Nutrition (an initiative of the AfDB) in partnership with the African Union launched the Continental Nutrition and Accountability Scorecard as part of its political commitment to nutrition outcomes (AUC-AfDB 2019). The recent AU-FAO Ministerial Meeting elaborated in its Declaration the key elements of value chains relating to fisheries and aquaculture during COVID-19 intervention measures (AUC-FAO 2020a, b, c, d, e). These global, continental, and regional frameworks and agreements provide strong guidance and targets for realising the potential of fisheries and aquaculture for the continent, and direct policy responses to be aligned with individual countries and their regional entities to respond to the pandemic.

Multiple financing instruments can be used to address crisis and policy reforms relating to poverty issues through grants and/or loans and advisory roles. Support through programmed-based operations (PBOs) and budget support can take multiple forms depending on the development context and eligibility for the country in context. Their design and mechanisms are suitable towards pandemic situations for many reasons including (i) legitimacy and ownership by governments, (ii) a central policy instrument enabling holistic long-term planning; and (iii) facilitation of dialog between development partners and improving aid coordination and effectiveness. PBOs thus present itself as one of the most common and desirable financing instruments during such crises (AfDB 2012).

\section{Towards strategies for healthy aquatic foods and sustainable supply chains}

Given the continental necessity for seafood security and the high level of food imports (Smith et al. 2010), it is crucial to maintain functional supply chains amidst lockdowns and border closures. The continent is becoming a food and nutritional hotspot, owning to severe import dependence, according to recent reports from the United Nations Conference on Trade and Development. The ratio of basic food balance to total merchandise export is the least in the world with most agri-commodities including fisheries been imported. In the pre-COVID-19 era, between 2016 and 2018, about $85 \%$ of staple and non-staple food was imported to the continent (Bichetti et al. 2021). With COVID-19 impacting export restrictions and supply chain disruptions, a new food price spike is predicted. Integrated responses can be implemented during this pandemic to augment public health interventions and to nourish nations as shown in Table 1.

Response measures and priorities may differ depending on the country's needs, production systems, and target species and product types. In all, it is important that focus on increased access to locally produced fish and fish products be encouraged through enacting gender sensitive policy reforms prioritizing fisheries and aquaculture in national food and nutrition security plans (Bolton et al. 2021). A review and analyses of existing policies and strategies indicate that provision of aquaculture inputs, training, and capacity building of value chain actors, adopting a minimum retention policy for landed fish for local consumption, zero waste or $100 \%$ utilization of discards, and provision of sanitary equipment for safety of workers and improved food safety are central in nourishing nations and fostering economic recovery.

For the SSF sub-sector, immediate and short-term responses seem ideal in meeting food and nutritional security (Bennett et al. 2020). Such can be achieved through increased harvest of sustainable and nutrition sensitive marine species such as herring and mackerel as well freshwater pelagics including Kapenta, Usipa and Daaga. Such support measures could include boosting output infrastructure and marketing technologies for reducing post-harvest loss and increasing value and competitiveness. Thus, it is not surprising to see an increase in trade over the years in cured ("dry" and/or "smoked") fish in Western Africa for marine species prior to the pandemic (Ayilu et al. 2016) as well as in the Great Lakes region for fresh water species (Kolding et al. 2019). Although there is evidence of benefits 


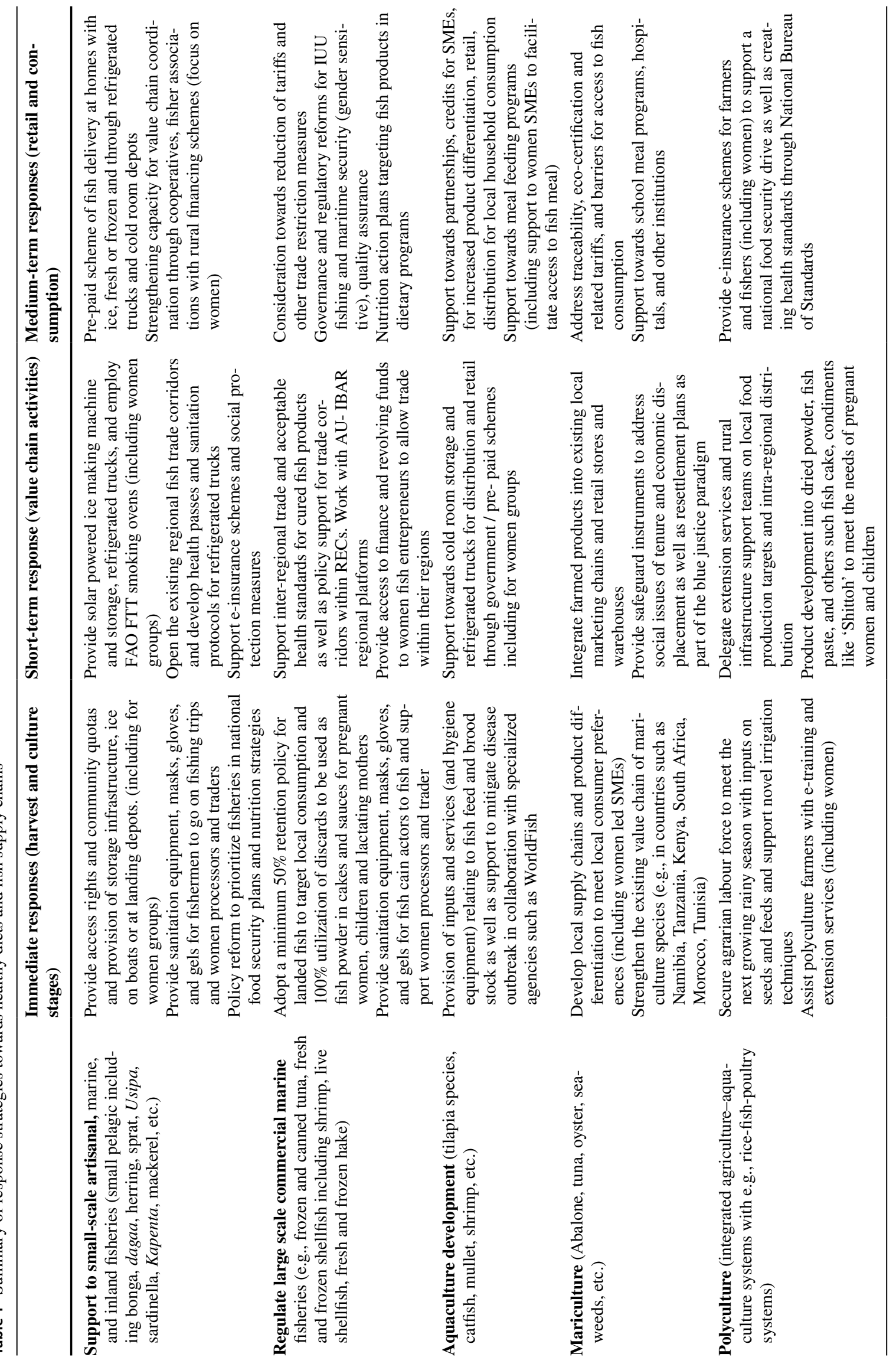


towards fisheries trade and food security through increased revenues and export earnings (Kurien 2005), issues around trade-off and unsustainable practices undermine the viability of African fisheries (Sumaila et al. 2020; NFDS 2008). As often argued, the viability and sustainability of SSF are critical to household fish consumption (Jentoft and Chuenpagdee 2015), towards cross-border trade and the livelihoods they support especially under COVID-19 response measures (FAO 2020c). Also important is securing catch quotas within sustainable harvest strategies and access to local markets. Moreover, e-commerce provides an opportunity for access to fish products through on-line platforms such as Facebook and retail home delivery during public health measures.

Similar to capture fisheries, boosting aquaculture production is both an immediate and long-term response strategy. Given that aquaculture is the fastest growing food industry in the world, it is still in its nascent stages on the continent, despite the geographical and environmental suitability for commercial production and financing opportunities. Recognizing this potential, there are now emerging public (and private) investments in cage and pond culture technologies, hatcheries development, and enterprise support in value chain development in riparian countries including Malawi, Zambia, Zimbabwe, Burundi, Democartic Republic of Congo, and Uganda amounting to more than one hundred million dollars. Similar investments across riparian and coastal systems towards sustainable and integrated aquatic food systems using the nexus approach and polyculture systems could contribute to nutritional wellbeing and regional trade.

Increasing momentum for aquaculture development on the continent is evidenced by the establishment of different stakeholder organizations and partnerships across multiple scale. Based on a need assessment by aquaculture practitioners for a multi-stakeholder platform, the African Chapter of the World Aquaculture Society (WAS-AC) was established in late 2018 and is hosted by the AUDA-NEPAD. The African Chapter offers a platform for inclusive membership and international networks, bringing together a wide variety of aquaculturists from the small-scale, commercial, research community and government sectors. The WAS-AC provides leadership for enhanced international communications, collaboration, and information exchange.

Moreover, the African Union has long prioritized fisheries and aquaculture as key sectors for Africa's development, recognizing in 2011 that the value added by the fisheries and aquaculture estimated at more than US $\$ 24$ billion, $1.26 \%$ of the GDP of all African countries, and as high as $10 \%$ in countries like Sierra Leone (AUC-NEPAD 2016). In fact, the African Union (AU) adopted the Policy Framework and Reform Strategy (PFRS) for Fisheries and Aquaculture that provides strategic guidance for the development of these sectors in Africa back in 2014. To support the implementation of the PFRS, the AU through the Inter-Bureau for Animal Resources (AU-IBAR) and the AU Development Agency - New Partnership for African Development (AUDANEPAD) implemented two priority initiatives. One focused on "Strengthening institutional capacity to enhance governance of the fisheries sector in Africa" and the related other on "Improving Food Security and Reducing Poverty through Intra-regional Fish Trade (Fish Trade). These projects were implemented between 2013 and 2018. The Fish Trade project aimed to enhance the capacities of regional and pan-African organizations to better integrate intraregional fish trade into their development and food security policy agendas. The two initiatives, both targeting medium and long-term commercial needs, have enabled tangible achievements, and built significant momentum towards improving both stakeholder engagement and policy action for improvement. As a follow-up to these initiatives, in 2021, the African Union launched a second phase of the Fisheries Governance project with the overall objective to enhance the contribution of sustainable fisheries and aquaculture within the sphere of Africa's Blue Economy Strategy and to the achievement of the AU Agenda 2063's objectives.

Indeed, supporting aquaculture development to meet the continent's nutritional needs has been the cornerstone of national development plans, given Egypt is today the topmost aquaculture producer in Africa contributing over $71 \%$ of the continent's farmed fish. This production is mainly based on tilapia for which globally, it is the third largest tilapia producer after China and Indonesia (FAO 2015). The rapid growth in farmed fish production in Egypt $(139,389$ tons in 1998 to $1,561,457$ tons in 2018) is a good example that African countries can emulate best production practices to meet their development target (FAO 2020a). The upward trajectory of production in Egypt can be attributed to the efforts Government of Egypt to train a number of its young scientists in 1980s, provision of quality feed and seed, and other inputs. Moreover, the establishment of the WorldFish Regional Center for Africa at Abbassa in 1998 has facilitated an innovation hub to promote research for development. Research support which produced the Genetically Improved Abbassa Nile Tilapia and best aquaculture training across the country saw an increasing production of affordable fish and local consumption in Egypt and across the continent (Ibrahim et al. 2019).

Through the partnership with WorldFish under the Technologies for African Agriculture Transformation (TAAT) flagship program with AfDB, Abbassa has become pivotal in enabling African government and entrepreneurs access cutting edge scientific advancement through continent-wide transfer of innovation and technologies. The program has seen several countries including Zambia, Malawi, Ghana, and Kenya which develop their own fish genetic improvement programs and increase national fish production from 
fish breeding and farming. As part of the achievements of TAAT compact with WorldFish, more than 200 demonstration sites have been established for technology display, with over 253,000 beneficiaries in 12 countries (Burundi, Cameroun, Cote d'Ivoire, Democratic Republic of Congo, Ghana, Kenya, Malawi, Nigeria, Republic of Tanzania, Benin, Togo, and Zambia). In addition, over 23,000 people have been trained on specific aquaculture technologies, with over 159 million fingerlings of catfish and tilapia of improved brood stock produced and distributed. The improved post-harvest technologies and product development includes solar tent drying techniques, smoking kiln technology, in-pond race way, cage culture techniques, recirculation techniques, raised pond technology, as well as in-pond race way and quality low-cost fish feed formulation and production. Four extension manuals on aquaculture technologies have been written by the Compact team for further training.

Within the medium and long-term response towards large scale commercial fisheries, multi-level governance and institutional strengthening is important in formulating harmonized standards and regulatory frameworks to address issues around overfishing through illegal, unregulated, and unreported (IUU) fishing. For example, through the Regional Economic communities, member states have ratified charters and strategies to implement the International Port State Measures Agreement to deter IUU as well as develop regional strategies to facilitate traceability, product development and cross-border trade. This is evident in both the Western and Southern regions, with centers established in Ghana (Tema) and Mozambique (Maputo), respectively.

As part of long-term interventions to promote resource sustainability and natural capital assets, in response to various drivers of global change, the United Nations (UN) Environment has encouraged the implementation of "effective and equitable" Marine Protected Areas in order to stabilise wild capture fish stocks and ecosystem functioning. This mandate is aligned in particular to target 14.5 of Sustainable Development Goal 14. To this end, the Contracting Parties of the Convention shall endeavour to establish protected areas, such as parks and reserves, and to prohibit or control any activity likely to have adverse effects on the species, ecosystems or biological processes in such areas. The convention countries have since developed individual strategies and actions to increase resource conservation. In Côte d'Ivoire, the country's first Marine Protected Area was created in December 2020, in the area of Grand Bereby, in order to respond to the important land-based pressures, including the overexploitation of fisheries resources which, in addition to the negative effects on the economy, has led to ecological imbalances such as the depletion or decline of predatory and wild fish stocks (Sankaré and Bamba 2016). To ensure cross-cutting protection and define a common methodology, the Abidjan Convention is part of a wider process currently ongoing between Benin and Togo and Côte d'Ivoire and Ghana to ensure that ecological and biological sensitive areas are protected and functional and acts as climate buffers. Similar efforts have been undertaken under the Nairobi Convention that addresses issues in the South West Indian Ocean to the coast of Somalia and the Red Sea ecosystem region.

In these response mechanisms, integrated agriculture-aquaculture approaches using polyculture systems have shown to increase production and productivity, such as in Tonkolili District in Sierra Leone, and create synergies between land-water resource management and integrated livelihoods (Kassam et al. 2017). Rice-fish farming techniques have proven to improve on household dietary intake and health outcomes as well as create additional income and livelihood opportunities with horticulture and animal husbandry (HLPE 2016). Moreover, creating demand for consumptions of fish can be realized through predictive markets such as school feeding programs, a large safety net reaching 65.4 million children in Africa (State of School Feeding 2020). School meal programs involving dry fish and other aquatic foods have the potential to create demand and create income along value chains where women play a significant role as entrepreneurs and household heads.

From a governance standpoint, community empowerment schemes championed by local governments and knowledge institutions could strengthen leadership and training of industry professionals and their organizations. Stakeholder participation in the governance of the sector is a vital element in the best management principles. AU-IBAR and AUDA-NEPAD has supported stakeholder participation by facilitating the establishment of regional non-state actors' platforms in West, Central, East, and Southern Africa. The establishment of these platforms has strengthened their capacities for coordinating national platforms and recognition by the state actor responsible for fisheries management and aquaculture development. These platforms greatly contribute in articulating the needs and demands arising in fishing communities in national, regional processes and continental processes (FAO 2020e). In addition to these, the African Women Fish Processors and Traders Network contributes towards improving the welfare, working conditions and income for women in the fisheries and aquaculture sector especially in the post-harvest and marketing domains.

Capacity building to create awareness of the importance of good nutrition and the opportunities for boosting food security and nutrition is needed at the local level, and also to create synergies between nutrition, food systems, and health linkages. Akin to agrarian activities, creating e-insurance policies for artisanal fishers and processors towards their health and livelihood is necessary and could be part of integrated interventions towards social protection in SSF and to SMEs (Mumford et al. 2009). 
This will complement initiatives to improve on access to finance through commercial banks, joint savings plans, cooperative schemes, union dues, and revolving funds.

Finally, the role of private sector in supporting priority actions along the fish value chain has been recognized by the High-level panel of experts (HLPE 2014). This could entail both public and private interventions in infrastructure and innovation targeting processing, storage and retail networks. Although the public sector was identified by the Panel as operating with a range of policy instruments to correct market failures, the private sector interventions, when well aligned, are quite effective to target value chains infrastructure through certification and product upgrade, labeling and packaging, and innovative business models. Generally, the private sector is known for heavily investing in food system R\&D and is increasingly interested in infrastructure upgrading to ensure environmentally and socially sustainable supply chains. This could lead to co-investment with public funds around key sustainability issues including climate resilience and blue financing. In the post COVID pandemic, financing platforms such as the AUDA-NEPAD "Grow Africa" should be promoted as they provide possibilities for partnerships in value chain development, create catalytic funds for bankable projects on agri-commodity value chain and organize towards Public Private Partnerships or Business to Business arrangements for non-sovereign investments.

\section{Discussion and policy recommendations}

Given the multiple entry and exit points for nutrition sensitive interventions (HLPE 2014, 2017), policy recommendations for nourishing nations with aquatic foods permeates along the supply chain but could also look at the food environment and consumer behavior. Immediate and long-term responses that prioritize aquatic food and dietary measures towards COVID-19 are strategic approaches that could yield long-term human capacity development and resilient economies. Despite the financial burden of dealing with supply chain disruptions and maintaining healthy diets, opportunities do present themselves for reform policies towards sustainable local food systems as well as livelihood security. Thus, it is imperative to prioritize nutrition sensitive investments that could support nutritional well-being, livelihoods and social inclusion, intra-regional trade, and resilient economies (as shown in Fig. 2). Five key recommendations are provided in building on current response measures to long-term community well-being and sustainable fish supply chains.

\section{Adopting a diet quality lens to grey matter infrastructure}

COVID-19 has highlighted how inter-connected our health and local food systems are, especially in building resilience through aquatic food systems (Bolton et al. 2021). Aquatic food systems that promote healthy diets play an important role in preventing all forms of malnutrition and in building immunity and physical well-being (Thilsted et al. 2016; Hicks et al. 2019). Aspiring to create resilient food systems after a period of crisis and disruption often entails reorganization and reform strategies towards sustainable local production and monetary policy reform to increase competitiveness (Bennett et al. 2020). This is crucial for governments to meet their commitments to support national food production systems, as per the Malabo commitment (10\% GDP expenditure), in reducing hunger and malnutrition, and nurturing grey matter infrastructure and human capital development (AfDB 2018). Indeed, fostering the goals of CAADP towards meeting the $6 \%$ target of fish resources' contribution to agriculture growth on the continent is necessary for food and nutrition security and to generate revenues and export earnings (AUC-NEPAD 2016). Some of the initiatives with African Leaders for Nutrition that involves scorecard on milestones achieved and advocacy programs through nutrition champions have helped to raise awareness and policy dialog on nutrition issues on a national and regional stage.

Increasing consumption of fish and aquatic foods and its addition to the staple dominant diets of low-income populations (including pregnant and breastfeeding mothers and young children) offers an important means for improving dietary diversity thereby contributing to food and nutrition security. For example, only 6 g portion size of dried small fish is needed to meet an average of $33.3 \%$ of requirements across multiple micronutrients as shown in research conducted in East and Southern Africa (White et al. 2021). Thus, fish, even in small quantities, is important in its in contribution to sustainable healthy diets, in preventing illness, and in its building, resilience cannot be overlooked.

\section{Supporting local food systems and program interventions}

A comprehensive Blue Economy investment plan for aquatic food systems is needed both within Regional Economic Community mandates and with national economic development plans. Such Blue Economy investment plans, as part of CAADP mandates, can also align with and update national nutrition strategies with the inclusion of aquatic foods such as fish as part of the national food-based dietary guidelines and food reserves. National school meal programs and other nutrition and food drives for the most vulnerable are needed with fish as central dietary intake. 
COVID-19 crisis may act as a catalyst to spur fisheries investments in sub-Saharan Africa, enabling countries to reduce their dependence on fish imports. This can be achieved through strengthened partnerships with international agencies, on brood stock enhancement programs, feed formulation, post-harvest utilization, hygiene and sanitation, private sector partnerships, as well as in securing local and regional markets. It is worthwhile to develop access rights to multi-user zones for small holder fish famers as well as aquaparks under land use reforms. Also important is to ensure that environmental and social safeguards are in adherence to national best practices towards critical habitats, biodiversity, resource sustainability, and synergies with climate adaptation across the fish supply chain (Khan et al. 2016).

Recognizing the contribution of SSF to household consumption and women SMEs, especially in the processing and marketing of fish (Kawarazuka et al. 2016), it is important to implement the FAO Voluntary Guidelines for Securing Sustainable Small-Scale Fisheries in the Context of Food Security and Poverty Eradication (FAO 2015) and employ it as a benchmark to promote sustainable local food systems. We are learning more about good practices on how governments are promoting food sovereignty through output services and distribution networks in meeting the healthy needs and high standards of vulnerable populations (FAO 2020d).

\section{Promoting regional approach to health standards along supply chains}

Regional bio-security plans for aquaculture production and trade corridors will require common standards on aquatic animal health: fish disease, safety, and quality, as well as improved handling, preservation, and processing techniques (FAO 2018). This will enhance distribution networks in regional markets and lead to the establishment of functional one-stop-border post protocols for maintaining phytosanitary best practices using digital technology, barcoding, and traceability techniques. This will also facilitate intra-regional trade through "blue ports" and "green corridors" with the ratification of AfCTA. This is one of the largest trading zones established in the world with the goal of creating a single market for 1.2 billion USD people with harmonized standards in agri-commodity trade with a total combined GDP of 2.5 trillion USD. To facilitate intra-regional trade of fish products and the harmonization of standards, WorldFish in partnership with the African Organization of Standardization have developed voluntary standards in key aquaculture products to booster consumer confidence on safety and quality using the EcoMark label.

The Comprehensive Strategic Framework for Sustainable Fisheries and Aquaculture Development under the ECOWAS Agricultural Policy is a regional example on how to mainstream fisheries and nutrition-sensitivity in food and nutrition security policy (ECOWAS Commission 2019). Another example is the Southern African Development Community's Regional Agricultural Policy (SADC 2013), which through implementation of the SADC Food and Nutrition Security Strategy (SADC 2014), is exploring ways to mainstream fisheries into national food and nutrition policy dialogs, with ultimate aim of including fish in the national community food basket (SADC 2020).

\section{Sustaining demand and consumption for fish and other aquatic foods}

While fish and other nutritious aquatic foods are available and accessible on the supply-side, demand from consumers is also a precondition for quality and quantity under sustainable harvest regimes. Although fish is widely consumed, its consumption follows preferences, cultural habits, and convenience, and is influenced by household decision-making and gender dynamics (HLPE 2017). Introducing fish as part of school menus can stimulate demand and foster intergenerational behaviors and consumption habits on healthy diets. Building demand for diverse nutritious diets and complementary services along the fish supply chain is critical. A gender-transformative social and behavioral change is advocated for, to safeguard household consumption, and to secure value chain stewardship. Moreover, addressing food waste and post-harvest loss is necessary, with efficient proven technologies targeting cold room chains as well as local fish curing including dried and smoked fish using FTT oven models. Local consumer preference is important and strategies to increase dietary intakes. This could include product differentiation of multiple fish and aquatic food products such as fish powder, fish cakes, fish sauce in vegetable oil and tomato sauce (e.g., Shitto), as well as promoting local canning and processing factories. However, this will require opportunities for entrepreneurial skills, particularly for women and youth, and fiscal incentives for start-up capital, lines of credit, guarantees, and private sector partnership including for women led enterprises towards joint ventures (FAO 2020e).

Moving forward, there is a need for a rapid assessment of fish and other aquatic foods value chains on the nature of implementation of response measures, understanding the dynamics of shifting markets and dietary consumer preferences, as well as procurement and logistical support towards "green corridors" and "blue ports" in the light of border closures and supply chain disruption.

\section{Developing and nurturing inclusive and multi-level partnerships}

Partnership within countries and across regions could promote coordination and resource mobilization as articulated under the Africa Food Security Leadership Dialogue. 
National donor platforms can also be avenues of change through joint programming, co-financing, and influencing policy reforms and best management practices. Women and youth are at the heart of this intersectionality, and approaching this crisis requires revisiting traditional strategies to include them as full-fledged actors, giving them resources adapted to their needs. An innovative gender transformative approach, including in research, is recommended to tackle the underlying causes of gendered inequalities along fish and other aquatic foods supply chains, capture fisheries and aquaculture system. Emerging findings indicate that transformative approaches may contribute to more potent gender outcomes and promote women's empowerment (Frangoudes et al. 2019). The approach requires multiple norms according to cultural contexts and implies gender mainstreaming as an integral part of fisheries and aquaculture development strategies (WorldFish 2012). These approaches should complement technical innovations such as availability of finance, and access to extension and technical services. New measures could entail creating spaces for CSOs, for women fish workers and their organizations, to participate in monitoring their implementation, and relevant organizational development support (FAO 2015; 2020e).

\section{Conclusion}

This paper provided an overview of the COVID-19 impacts on fisheries and aquatic food systems and its role in nourishing nations as "super foods." Overall, the evidence shows the importance of strengthening the food-nutrition-health nexus with an emphasis on (i) the development of nutrition sensitive food system programmes that promote healthy diets in preventing all forms of malnutrition; (ii) support local food systems and programmes interventions with comprehensive blue economy investments plans for aquatic food systems at both national and regional levels within RECs mandate as part of the CAADP process; (iii) promote regional approach to health and safety standards along strategic fish value chains and other agri-food systems; (iv) sustain supply and consumption of aquatic foods; and (v) develop an inclusive and multi-level partnerships that is capable of resource mobilization and funding coordination towards fish supply chain activities.

In supporting recovery, through collaborative approaches and partnership platforms, it has been recommended to address food and nutritional security through policy advocacy, program alignment, and targeting nutritional hotspots and food reserves through development financing (AUCFAO 2020a). All multilateral development banks and development partners agreed to invest in the establishment of ad-hoc facilities (for input and out infrastructure needs), leveraging of resources and partnership financing (e.g.,
Global Agriculture and Food Security Program) and repurposing existing funds and ensuring synergies of interventions (AfDB 2020). Eighteen months into the pandemic, one can identify various investments in food and inputs supply, reduction of post-harvest losses, cash-based safety nets, as well as market related interventions, aimed to avoid supply chain disruptions.

As the impacts of these partnerships are reviewed, monitored and evaluated over the next decade; new insights are needed on the types of partnerships required, both old and new, at multiple scales, and how to strengthen collaboration for program delivery in curbing the pandemic and in nurturing and nourishing healthy communities.

This is a novel area of policy dialog and applied research of interest to and in support of the Manifesto of the Marine Social Sciences and with a specific focus on the role of fisheries and the blue economy in African's transformational development.

Acknowledgements The editorial inputs and contributions from Dr. Elizabeth Wangui Goro of the of the Department of Agriculture Finance and Rural Development (AfDB) are greatly appreciated. Dr. Andrew Mude provided invaluable comments and suggestions that improved the quality of the paper. Two anonymous reviewers provided useful feedback and suggestions that has improved the quality of the Paper. Florine Lim provided an update in Figure 2.

\section{Declarations}

Conflict of interest The authors declare no conflict of interest.

Disclaimer This is a collaborative and supplementary contribution to the African Development Bank Group 'Feed Africa Response to Covid19 (FAREC)' road map, expounding on aquatic food systems in the Blue Economy towards nutrition, livelihoods, and regional trade. The findings and opinions expressed in this Brief are entirely those of the authors and not the position of their institutions and organizations.

\section{References}

AFDB. 2018. Multi-Sectoral Nutrition Action Plan 2018-2025. Harnessing the grey matter infrastructure to unlock the human and economic potential of africa: catalyzing nutrition smart investments to support stunting reduction in Africa by 2015. Abidjan.

AfDB 2020. Feed Africa Response to COVID-19 Brief. Department of Agriculture \& Agro-Industry and the Department of Agricultural Fonance and Rural Development. African Development Bank Group, Abidjan.

AUC-NEPAD. 2016. Policy framework and reform strategy for fisheries and aquaculture in Africa. African Union Commission. Addis Abbaba.

AUC-AfDB. 2019. African Leaders for Nutrition Score Card. AUC, Addis Ababa.

AUC-FAO. 2020. Ministerial Declaration on Covid-19 response. AUC, Addis Ababa.

AU-IBAR 2018. Strategy for rational management of African inland fisheries. AU-IBAR Reports, Nairobi. 
AU-IBAR. 2020. Africa Blue Economy Implementation Plan, 20212025. Nairobi.

Ayilu RK, TO Antwi-Asare, P Anoh, A Tall, N Aboya, S Chimatiro, S Dedi. 2016. Informal artisanal fish trade in West Africa: Improving cross-border trade. WorldFish Program Brief, Penang. 2016-37.

Bavinck, M., and J. Verrips. 2020. Manifesto for the marine social sciences. Maritime Studies 19: 121-123.

Bennett, N.J., A.M. Cisneros-Montemayor, J. Blythe, J. Silver, et al. 2019. Towards a sustainable and equitable blue economy. Nature Sustainability 2: 991-993.

Bennett, N.J., E.M. Finkbeiner, N.C. Ban, D. Belhabib, S.D. Jupiter, J.N. Kittinger, S. Mangubhai, J. Scholtens, D. Gill, and P. Christie. 2020. The COVID-19 pandemic, small-scale fisheries and coastal fishing communities. Coastal management 48: 336-347.

Black, R., L. Allen, B. Zulfiqar, L. Caulfield, Mercedes de Onis, E. Majid, M. Colin, and J. Rivera. 2008. Maternal and child undernutrition: Global and regional exposures and health consequences. Lancet 371: 243-260.

Bolton, R., R. Leah, L. Middleton, S. Ghazali, A. Mamun, S. Jacqueline, H. Noronha, G. Dhar, I. Mohammod, P. Christopher, N. Ahmed, E. Ibrahim, B. Bikram, P. Arun, R. Suresh, A. Mohan, R. Babu, M. Akester, and S. Thilsted. 2021. COVID-19 impact and adaptation in Asia and Africa's aquatic food value chains. Marine Policy 129: 104553.

Brechitti D, C Razo, M Shirotori. 2021. Trade and food security: when an agreement delayed becomes a human right denied. UNCTAD News. Available at https://unctad.org/news/trade-and-food-secur ity-when-agreement-delayed-becomes-human-right-denied accessed June 29th 2021.

Coulthard, S., D. Johnson, and A. McGregor. 2011. Poverty, sustainability and human wellbeing: A social wellbeing approach to the global fisheries crisis. Global Environ Change 2: 453-463.

ECOWAS Comission. 2019. Comprehensive strategic framework for sustainable fisheries and aquaculture development. Ecowas Agricultural Policy Unit.

Frangoudes, K., S. Gerrard, and D. Kleiber. 2019. Situated transformations of women and gender relations in small-scale fisheries and communities in a globalized world. Maritime Studies 18: 241-248.

Frangoudes, K., S. Gerrard, and A. Said. 2020. Commentary 6 to the Manifesto for the marine social sciences: Gender and the role of women. Maritime Studies 19: 137-138.

FAO. 2013. Mainstreaming gender in fisheries and aquaculture, a stocktaking and planning exercise, final report. Rome: FAO.

FAO. 2015. Voluntary guidelines for securing sustainable small-scale fisheries in the context of food security and poverty eradication. Rome: FAO.

FAO. 2018. Development of a Regional Aquatic Biosecurity Strategy for the Southern African Development Community (SADC) FAO Fisheries and Aquaculture Circular No. C1149. Rome: FAO.

FAO. 2020. State of World Fisheries and Aquaculture. Rome: FAO.

FAO. 2020. Food and nutrition brief on Covid19 responses. Rome: FAO.

FAO. 2020. Agri-food markets and trade policy in times of Covid-19. Rome: FAO.

FAO. 2020. Fisheries and aquaculture brief. Rome: FAO.

FAO. 2020e. Report of the PAN-African workshop on strengthening organizational structures of non-state actors for sustainable smallscale fisheries in Africa. Kasane, Botswana, 10-12 July 2019. Fisheries and Aquaculture Report No. R1288. Rome.

GFSC. 2020. Global Report on Food Crisis 2020. New York: United Nations.

Global Nutrition Report 2018. Initiatives Development, 2018 Global Nutrition Report: shining a light to spur action on nutrition. Bristol: Development Initiatives.
Global Nutrition Report. 2020: Action on equity to end malnutrition. Bristol, UK: Development Initiative.

Harper, S., D. Zeller, M. Hauzer, D. Pauly, and R. Sumaila. 2013. Women and fisheries: Contribution to food security and local economies. Marine Policy 39: 56-63.

Hicks, C., P.J. Cohen, N.A.J. Graham, et al. 2019. Harnessing global fisheries to tackle micronutrient deficiencies. Nature 574: 95-98.

HLPE. 2014. Sustainable fisheries and aquaculture for food security and nutrition. A report by the High Level Panel of Experts on Food Security and Nutrition of the Committee on World Food Security, Rome.

HLPE. 2016. Report on sustainable agricultural development for food security and nutrition: what roles for livestock? A report by the High Level Panel of Experts on Food Security and Nutrition of the Committee on World Food Security, Rome.

HLPE. 2017. Nutrition and food systems. A report by the High Level Panel of Experts on Food Security and Nutrition of the Committee on World Food Security, Rome.

Ibrahim, N.A., A.M. Nasr-Allah, and H. Charo-Karisa. 2019. Assessment of the impact of dissemination of genetically improved Abbassa Nile tilapia strain (GIANT-G9) versus commercial strains in some Egyptian governorates Aquaculture. Research 50 (10): 2951-2959.

Jentoft, S., and R. Chuenpagdee. 2009. Fisheries and coastal governance as a wicked problem. Marine Policy 33: 553-560.

Jentoft S, R Chuenpagdee. 2015. Interactive governance for small-scale fisheries. Elsevier.

Johnson D, T Acott, N. Stacey, J. Urquhart. 2018. Social well-being and the value of small-scale fisheries. Elsevier.

Kassam L,K Lakoh, C Longley, MJ Phillips, SN Siriwardena. 2017. Sierra Leone fish value chain with special emphasis on Tonkolili District. Penang, Malaysia: WorldFish. Program Report: 2017-33

Kawarazuka N, C Locke, C McDougall, P Kantor, P Morgan, M Bringing. 2016. gender analysis and resilience analysis together in small scale fisheries research: challenges and opportunities. University of East Anglia. DEV Working Paper Series.

Khan, A.S., and S. Sesay. 2015. Seafood insecurity, bush meat consumption, and public health emergency in West Africa: Did we miss the early warning signs of an Ebola epidemic? Maritime Studies 14: 3.

Khan, A., A. Charles, and D. Armitage. 2016. Place-based or sectorbased adaptation? A Case study of municipal and fishery policy integration. Climate Policy 18: 14-23.

Khan, A. 2020. Commentary 8 to the manifesto for the marine social sciences: Fishery resources in a development African context. Maritime Studies 19: 141-142.

Kolding J, F Van Zwieten, F Marttin, S Funge-Smith, F Poulain. 2019. Freshwater small pelagic fish and fisheries in major African lakes and reservoirs in relation to food security and nutrition. FAO Fisheries and Aquaculture Technical Paper N.

Kurien, J. 2005. Responsible Fish Trade and Food Security. FAO Fisheries Technical Paper. 456. Rome: FAO.

Larson K. 2002. The role of fiscal policy in crisis situations. IMF.

OECD. 2014. Measuring and fostering well-being and progress. Paris: OECD.

Sankaré Y, A Bamba. 2016. Etude contributive a la creation des aires marines protegees de l'afrique de l'ouest au sud du sahara : cas de la cote d'Ivoire. UN Environment, Abidjan.

Smith, M.D., C.A. Roheim, L.B. Crowder, B.S. Halpern, M. Turnipseed, J.L. Anderson, F. Acshe, L. Bourillon, A.G. Guttormsen, A.S. Khan, L.A. Liguori, A. McNevin, M.I. O'Connor, D. Squires, P. Tyedmers, C. Brownstein, K. Carden, and D. Klinger. 2010. Sustainability and global seafood. Science 327: 784-786.

Swinnen, J. 2020. Will COVID-19 cause another food crisis? An early review. s.1. : IFPRI. 
SADC. 2013. Regional Agricultural Policy. SADC Secretariat, Gaborone, Botswana.

SADC. 2014. Food and Nutrition Security Strategy (2015-2025). SADC Secretariat, Gaborone, Botswana.

SADC. 2020. Contribution of fisheries to food and nutrition security in the SADC region. Gaborone, Botswana.

Thilsted, S.A., A. Thorne-Lyman, W. Patrick, Jessica Bogard, S. Rohana, P. Michael, and A. Edward. 2016. Sustaining healthy diets: The role of capture fisheries and aquaculture for improving nutrition in the post-2015 era. Food Policy 61: 126-131.

Walson J L, JA Berkley. 2018. The impact of malnutrition on childhood infections. Wolters Kluwer Health, Inc., Vol. 31, 6.

White, J., T. Beal, J. Arsenautl, H. Okronipa, G. Hinnouho, K. Chimanya, M. Joan, and A. Garg. 2021. Micronutrient gaps during the complementary feeding period in 6 countries in Eastern and Southern Africa: A Comprenhensive Nutrient Gap Assessment. Nutrition Reviews 79: 16-25.

WorldFish. 2012. Gender strategy brief: a gender transformative approach to research in development in aquatic agricultural systems. WorldFish, Penang.
WFP. 2020. State of School Feeding Worldwide 2020. Rome: WFP. AfDB. 2012. Bank group policy on program-based operations. Operational Resources and Policies Department. AfDB, Abidjan.

Sumaila, U. R., Zeller, D., Hood, L., Palomares, M. L. D., Y Li, D Pauly. 2020. Illicit trade in marine fish catch and its effects on ecosystems and people worldwide. Science Advances, 6, 9 eaaz3801.

NFDS. 2008. Review of the performance of the current fisheries and aquaculture portfolio of the AfDB. . NFDS Consulting, Oslo : s.n.

Mumford, J. D., Leach, A. W., Levontin P., Kell, L. T. 2009. Insurance mechanisms to mediate economic risks in marine fisheries. ICES Journal of Marine Science, 66: 950-959.

Publisher's note Springer Nature remains neutral with regard to jurisdictional claims in published maps and institutional affiliations. 